\title{
LA INFANTA DOÑA MARÍA, MONJA DE SIJENA, Y SU POLÍTICA CASTELLANA DURANTE LA MINORÍA DE ALFONSO XI (1312-1325)
}

\author{
MANUEL GARCÍA FERNÁNDEZ \\ Universidad de Sevilla
}

\author{
SUMARIO \\ 1. La infanta Doña María en Castilla, 1312-1320.- 2. La infanta Doña \\ María en Aragón, 1320-1325.
}

A comienzos de 1322 la infanta aragonesa doña María, hija mayor de Jaime II, viuda del infante castellano don Pedro, que fue tío y tutor de Alfonso XI de Castilla, muerto trágicamente en la Vega de Granada en 1319, tomaba el hábito de San Juan de Jerusalén como monja del Monasterio de Sijena. Le acompañaba en su exilio su hija doña Blanca, de tan sólo dos años de edad, nieta tanto del rey de Aragón, como de doña María de Molina. Atrás quedaban las turbulencias nobiliarias de la compleja sociedad política castellana y sus intrigan cortesanas, las aspiraciones de poder y las banderías de los nuevos tutores del rey, el infante don Felipe, don Juan Manuel, don Juan el "tuerto", señor de Vizcaya, y sobre todo, los muchos intereses señoriales heredados de su esposo con sus cuantiosas rentas bajo el férreo control de García Lasso de la Vega, mayordomo mayor y albacea testamentario del infante don Pedro.

La personalidad difícil e independiente de la infanta aragonesa frente a su padre y su política peninsular, la figura excepcional de su hija doña Blanca, la infeliz prima boba aunque rica de Alfonso XI, objeto de fácil" 
negociación matrimonial para nobles y príncipes, y la trama doméstica, castellana y aragonesa, de todo este complicado asunto diplomático y dinástico ha sido suficientemente estudiado en su conjunto. En $1948 \mathrm{~J}$. Ernesto Martínez Ferrando publicó una extraordinaria monografía sobre la vida familiar de Jaime II de Aragón y sus hijos, con unas interesantes páginas sobre la infanta doña María, su matrimonio con el infante don Pedro, la defensa de sus patrimonios ante la sociedad política castellana de Alfonso XI, y sobre el incierto futuro de su hija doña Blanca'. En este mismo sentido en 1994 Ángeles Masiá de Ros aportaría nuevos datos mediante una revisión e interpretación más moderna y menos evenemencial de los viejos documentos editados y/o conocidos de antiguo, dentro del contexto general de las relaciones diplomáticas entre Castilla y Aragón en tiempos de Jaime II hasta Pedro IV el Ceremonioso².

Ambos trabajos, con sus respectivos estudios y textos, resultan hoy por hoy imprescindibles para nuestro objetivo, juntamente con algunos fragmento textuales y las noticias sueltas recogidas en 1932 por Andrés Giménez Soler en su clásica biografía sobre don Juan Manuel $^{3}$.

Sin embargo conviene recordar que por la procedencia de las fuentes utilizadas, exclusivamente cartas reales diplomáticas y registros de cancillería del ACA, resulta una visión y sobre todo una exposición muy parcial de los hechos históricos, desde una perspectiva aragonesa, no siempre coincidente con la óptica castellana de los acontecimientos. Se podría argumental con justicia que desgraciadamente en Castilla se carece de fuentes parecidas para el período que estudiamos. Pero una nueva lectura de los documentos conservados, sabiendo además la problemática castellana específica, nos descubre entre líneas un panorama inédito o cuando menos poco analizado de Castilla. Además en auxilio del investigador acude siempre la riqueza

'J. Ernesto Martínez FerRando, Jaime II de Aragón. Su vida familiar. Vol. I Texto, vol. II Documentos. Barcelona, 1948. y también J. BAUCELIS I REIG, L'expansió peninsular en la política de Jaume II. El matrimonio de la seva filla la gran amb l'infant Pere de Castella. "Anuario de Estudios Medievales", 12 (1982), pp. 491-535.

${ }^{2}$ Ángeles MASIÁ DE ROS, Relación castellano-aragonesa desde Jaime II a Pedro el ceremonioso. vol. I texto, vol. Il Apéndice documental. Barcelona, 1994.

${ }^{3}$ Andrés Giménez Soler, Don Juan Manuel. Biografia y estudio crítico, Zaragoza, 1932. 
temática, aunque a veces tendenciosa, de las crónicas nacionales de Fernán Sánchez de Valladolid, secretario de la poridad de Alfonso $\mathrm{XI}^{4}$.

Así pues, en las páginas que siguen hemos intentado ofrecer al lector una síntesis general de la sociedad política de la infanta doña María durante la minoría de Alfonso XI (1312-1325), que constituyen los años más importantes de su mediación castellana. No se trata de una biografía. Pues con pesar hemos suprimido el análisis exhaustivo de los asuntos privados y familiares, por otro lado bien conocidos, en beneficio de una exposición más amplia y general, a modo de reflexión y estado de la cuestión, y siempre que las fuentes lo han permitido, desde el rédito y la transcendencia castellana. Somos conscientes de nuestras limitaciones. Sabemos de la necesidad de reescribir la historia para poder avanzar con nuevos conocimientos en una época vital para Castilla en el umbral ya de la Baja Edad Media.

\section{La infanta Doña María en Castilla, $1312-1320$}

La hija mayor de Jaime II llegaría a Castilla a finales de enero de 1312 tras su reciente matrimonio con el infante don Pedro, hermano del rey castellano Fernando IV, en Calatayud. Para la historiografía aragonesa que se ha ocupado de este asunto -Martínez Ferrando, Baucelis i Reig y Masiá de Ros, entre otros- las prolijas negociaciones de la boda de doña María fueron siempre entendidas como un notable éxito político de Jaime II que situaría al rey de Aragón en una posición hegemónica entre los diferentes bandos nobiliarios de los tutores de Alfonso XI, los infantes don Juan y don Pedro, al tiempo que acrecentaba su prestigio peninsular ${ }^{5}$.

Como la infanta doña Constanza había sido ya prometida a don Juan Manuel - su matrimonio se realizaría en abril de 1312 en Játiva - el enlace entre doña María y don Pedro aseguraba y robustecía los vínculos dinásticos y políticos con Castilla, especialmente tras la grave enfermedad de Fernando

\footnotetext{
${ }^{4}$ Crónicas de los Reyes de Castilla. Ed. de Cayetano Rosell, Madrid, 1953. BAE. En el volumen I se editan las crónicas de Alfonso X, Sancho IV, Fernando IV y Alfonso XI obras todas ellas de Fernán Sánchez de Valladolid.

5J. Ernesto MARTíneZ FERrando, Jaime II de Aragón, ob.cit., p. 108, Ángeles MASIÁ DE Ros, Relación castellano-aragonesa, ob.cit., tomo I, p. 179.
} 
IV durante la primavera de 1311 y ante la inesperada apertura de una larga y complicada minoría en $1312^{6}$.

Pues sólo de esta forma se justificaba en Castilla las relativas prisas del rey de Aragón por concretar y ampliar la dote de su futuro yerno, sus presiones diplomáticas y los muchos manejos familiares, a través de diligentes embajadores, para asegurar los compromisos territoriales pactados con Fernando IV, y sobre todo para celebrar cuanto antes el matrimonio en Santa María de Calatayud con la presencia incluso del rey castellano ${ }^{7}$. En Calatayud ente Fernando IV y don Dinís de Portugal como testigos, Jaime II consolidaba su hegemonía peninsular, uno de cuyos pilares básico estaba en el deseado enlace de la su hija doña María con el infante don Pedro ${ }^{8}$.

Ahora bien, para la mayor parte de la sociedad política castellana, para doña María de Molina y sus partidaríos, las sonadas y solemnes bodas de Calatayud fueron consecuencia solamente de un difícil compromiso de estado. Unas nupcias que nunca fueron del afecto de los contrayentes, sino más bien del interés coyuntural de Fernando IV y Jaime II, y no tanto de la anciana reina, como tradicionalmente se venía afirmando por todos los que seguían la interpretación de A. Giménez Soler'.

En efecto, sin querer ser simplistas, pero pretendiendo buscar la esquematización del problema, resulta evidente que para doña María de Molina los esponsales, que aseguraban la mediación aragonesa en la turbulenta sociedad castellana, tuvieron como contrapartida la promoción política y social del infante don Pedro como tutor de Alfonso XI frente al infante don Juan y a don Juan Manuel. Pero, ¿realmente estaba la reina castellana tan satisfecha de la situación matrimonial de su hijo con la infanta doña María?, ¿ no sería una estudiada maniobra política para evitar dar a

\footnotetext{
${ }^{6}$ Crónica de los Reyes de Castilla. Crónica de Fernando IV, ob.cit., tomo I, pp. 167-168. Sobre este monarca se puede ver la completa síntesis de César GONZÁLEZ MínGUEZ, Fernando IV (1295-1312), Palencia, 1995.

${ }^{7}$ César González Mínguez, Fernando IV, ob. cit., pp. 236-237.

${ }^{8}$ Sobre la actividad diplomática de Jaime II durante la minoría de Alfonso XI y sus relaciones con la sociedad política castellana ver Manuel GARCÍA FERNÁNDEZ, Jaime II y la minoría de Alfonso XI (1312-1325). Sus relaciones con la sociedad política castellana, "Historia. Instituciones. Documentos" 18 (1991), pp. 143-181.

${ }^{9}$ Andrés GimÉnEZ SOLER, Don Juan Manuel, ob. cit. pp. 44-45. Sostiene este investigador que don Juan Manuel tenía recelos de la preponderacía que este casamiento daría al infante don Pedro, su rival en la lucha por la tutoría de Alfonso XI. Lo que en su opinión explicaría la excelente y fluida correspondencia entre doña María de Molina y Jaime II agradeciendo el apoyo que prestaba a su hijo don Pedro.
} 
Jaime II una visión pesimista, derrotista y confusa de Castilla que le animara definitivamente a una intervención directa?. Siguiendo al respecto la interpretación que en 1967 apuntara M. Gaibrois de Ballesteros, una revisión y nueva lectura de los documentos conservados en el ACA nos descubre cuando menos que, a pesar del clima de aparente cordialidad diplomática, la infanta argonesa nunca mantuvo buenas relaciones con doña María de Molina, sus parientes y vasallos. Tampoco la reina confió en doña María, a pesar del reiterado interés de Jaime II por acercar las posturas de suegra y nuera, prueba evidente de que entre ambas mujeres existía ciertos recelos mutuos que terminarían por aurruinar la convivencia familiar ${ }^{10}$.

La Crónica de Férnando IV abunda con frialdad también en este asunto al señalar muy de pasada que: "entonces era tratado casamiento del infante don Pedro con doña María, fija del rey de Aragón", por entenderlo básicamente como parte de una gran alianza militar contra Granada porque "...los reyes amos pusieron pleito de facer guerra a los moros cada uno de su parte"11. Lo que nunca se concretó en nada positivo por la prematura muerte del rey castellano tan sólo unos meses después ${ }^{12}$.

En Castilla doña María entraría de lleno en la bandería de su esposo. A través de ella, don Pedro siempre pudo contar con el consejo, apoyo y protección política de su suegro, no vamos a insistir sobre el tema ${ }^{13}$. Pero en el concierto de los bandos nobiliarios castellanos, en las tensas negociaciones de los tutores, en las diferentes cortes -Palencia en 1313, Burgos en 1315 y Carrión en 1317- doña María suele estar presente aunque aparentemente juegue un papel muy secundario junto a don Pedro. Sometida a la autoridad del infante castellano y bajo el férreo control de doña María de Molina, a la que acompaña durante algunos avatares políticos y fronterizos de su marido ya en Ávila ya en Valladolid, la hija de Jaime II llevó una vida muy discreta, familiar y cortesana con frecuentes misivas a su padre sobre los más diversos asuntos de su nueva situación social y política ${ }^{14}$.

\footnotetext{
${ }^{10}$ Mercedes Gaibrois De Ballesteros, María de Molina, tres veces reina, Madrid, 1967, pp. 188-195. y J. Ernesto MARTínEZ FERRANDO, Jaime II de Aragón, ob. cit., pp. 109-110.

"Crónica de Fernando IV, ob. cit, pp. 168-169.

${ }^{12}$ César González Mínguez, Fernando IV, ob.cit., p. 237

${ }^{13}$ Sobre el asunto ver Manuel GARCíA FERNÁNDEZ, Jaime II y la minoría de Alfonso XI, ob.cit., pp.147-149 y pp. 159-160.

${ }^{14} \mathrm{ACA}$, Cancillería (en adelante C.), registro (en adelante reg.) número 241, fols. 144 r-145 v. Ángeles MASIÁ DE ROS, Relación castellano-aragonesa, ob. cit., p. 196.
} 
Desde su llegada a Castilla y a través del mayordomo mayor de don Pedro, García Lasso de la Vega, la infanta argonesa recibe poco a poco el vasallaje de las villas y los castillos patrimonio de su marido -Aguilar del Campoo, Fuentepudía, Almazán, Berlanga, Montegaudo, Deza y Serón, entre otros lugares ${ }^{15}$. Sin embargo, el interés de Jaime II por acercar a su hija a la órbita política de Lasso de la Vega nos descubre una vez más que, de igual manera que con doña María de Molina, la infanta aragonesa se muestra díscola a las gestiones económicas de su mayordomo mayor. El tiempo le daría la razón. García Lasso de la Vega era un hombre próximo al pensamiento político de la reina y más tarde del infante don Felipe, enemigo de toda influencia aragonesa en la administración de los patriomios castellanos de don Pedro. Por lo que siempre que puede, doña María, contraria a imposiciones ajenas, elude la tutela de doña María de Molina, la vigilancia de García Lasso de la Vega y acompaña bajo cualquier pretesto a su esposo a la Frontera. En 1317 está en la ciudad de Córdoba donde el infante don Pedro preparaba algunas acciones militares contra Granada. O bien se refugia en la comprensión y el cariño familiar de su hermana doña Constanza, esposa como ya sabemos de don Juan Manuel ${ }^{16}$.

Desde 1312 a 1319 la infanta doña María sólo encuentra amparo en don Pedro. La frialdad de doña María de Molina y sus partidarios, la desconfianza y el desde de muchos nobles castellanos acrecientan esta dependencia y la insertan definitivamente en el futuro político de su esposo. Jaime II lo sabía, y también don Pedro. Ambos intentarán sacar provecho de la mediación de la infanta en Castilla y Aragón, respectivamente.

En el verano-otoño de 1319 varios sucesos vinieron a complicar la situción política, la vida social y económica de la infanta, a acrecentar su soledad, a extender su recelos y en gran medida su desesperación en la corte castellana.

Como es bien sabido, el 25 de junio de 1319 una expedición cristiana contra Granada, que encabezaban los infantes don Juan y don Pedro resultó ser un estrepitoso fracaso militar con la muerte incluso de ambos tutores. El suceso fue muy conocido ya en su pripio tiempo porque la conmoción fronteriza y militar fue enorme en toda Castilla y también en

\footnotetext{
278.

${ }^{15}$ Ángeles MASIÁ DE ROS, Relación castellano-aragonesa, ob.cit., p. 183 y tomo II, p.

${ }^{16} \mathrm{ACA}$. C, cartas reales (en adelante cr), ns. 5373 y 5377. Gran Crónica de Alfonso XI. Ed de Diego Catalán, Madrid, 1976, tomo I, pp. 302-304.
} 
Aragón ${ }^{17}$. La infanta daña María, que había acompañado a su esposo a Andalucía, tuvo noticias de la muerte de don Pedro en Córdoba. La Gran Crónica de Alfonso XI nos informa que "los que trayan al ynfante don Pedro - pusieronlo en vn mulo atrauesado - aportaron con él a Priego, e dende fueron se para Vaena, e de Vaena leuaronlo a Arjona. E enbiaronlo dezir a la ynfanta doña María, su muger, que estaua en Córdoba, e estaua en días de encaesçer, e por que era peligro de la traer a su enterramiento, non la quisieron atender los vasallos del ynfante don Pedro, e leuaronlo a enterrar al monasterio de las Huelgas de Burgos a do se mandó enterrar"18.

La trágica muerte del infante don Pedro privaría a doña María de su principal valedor ente la altiva sociedad política castellana, especialmente ahora que la infanta estaba en cinta. Su bandería política, a la que tanto y tan bien había servido fue pronto encabezada por el infante don Felipe, que contaba además con el decidido apoyo de su madre la reina doña María de Molina. Pero su cuñado era un hombre contrario a la influencia aragonesa en Castilla, desconfiaba de Jaime II y su pretendida hegemonía peninsular. El infante, señor de Cabrera, Ribera y Pertiguero Mayor de Santiago, fue aglutinando a todos aquellos nobles descontentos con don Juan Manuel y con el rey de Aragón, pues tras la desaparición de don Pedro el señor de Peñafiel se había convertido en el principal candidato aragonés a la tutoría de Alfonso $\mathrm{XI}^{19}$.

En el proyecto político de don Felipe, la infanta doña María no entraba. Todos aquellos nobles, vasallos y amigos de don Pedro, que en algún momento justificaron cuando no alagaron la mediación aragonesa de doña María, la condenaban ahora, incluida lógicamente la propia doña María de Molina. La bandería de don Felipe, que integraba a ricos hombres de prestigio como Juan Rodríguez de Rojas, Fernán Ruiz de Saldaña, Rodrigo Alvarez de Asturias, Juan Martínez de Leiva, don Sancho, obispo de Avila, y a don Alvar Nuñez de Osorío, privado del rey y futuro conde de Trastámara, solo reparó en la infanta aragonesa la madre del futuro heredero del infante don Pedro y en algunos casos ni siquiera eso, sino la sombra

\footnotetext{
${ }^{17}$ Manuel GARCía FERNÁNDEZ, Andalucía, guerra y frontera (1312-1350). Sevilla, 1990 Andrés 'GIMÉNEZ SOLER, La expedición a Granada de los infantes don Juan y don Pedro en 1319, "Revista de Archivos, Museos y Bibliotecas", XI (1904), pp. 353-360 y XII (1905), pp. 24-36.

${ }^{18}$ Gran Crónica de Alfonso XI, tomo I, p. 318.

${ }^{19}$ Manuel García FernáNDEZ, Jaime II y la minoría de Alfonso XI, ob.cit., pp. 156-157.
} 
perturbadora de Jaime II. El vacío social y político que doña María experimentaba en Castilla le hacía desconfiar de todos. Su único interés estaba en el hijo que esperaba dar a luz muy pronto, dueño de vastos patrimonios, y cuyo tutor y custodia sería García Lasso de la Vega por voluntad testamentaria de su padre ${ }^{20}$.

El rey de Aragón sabía de la soledad de hija en Castilla que "finca muy jouen e muy mançeba e entre gentes de malos judiçios"21, de la que siempre estuvo muy bien informado ${ }^{22}$. Así se explica el interés por encomendar la viudez y los bienes de su hija a la reina doña María de Molina y al mayordomo García Lasso de la Vega. Y sobre todo la solicitud a Teresa de Urrea, priora de Sijena, del envio de dos dueñas a Castilla para hacer compañía a la infanta, nonjas que no sólo se retrasaron en acudir a su destino - agosto de 1319- sino que se manifestaban contrarias a permanecer en el mismo ya a los pocos meses -octubre de 1319-de su estancia ${ }^{23}$.

No creemos que fuera el temperamento independiente de doña María - como apuntaron J.E. Martínez Ferrando y A. Masiá de Ros- el causante de esta iniciativa tan paternalista, tan del estilo de Jaime II. Ni mucho menos que el carácter dificil de la infanta provocara el súbito descontento de la monjas de Sijena; sino que más bien fueron las circunstancias tan adversas en las que discurría la vida de doña María en Castilla. En efecto, la paulatina merma del patrimonio fronterizo con Aragón heredado de su esposo, la progresiva frialdad cortesana de doña María de Molina sin romper nunca la "formas diplomáticas", la inhibición económica de su mayordomo mayor García Lasso de la Vega, cuyas buenas palabras al rey de Aragón estaban vacias de intenciones, lo que unido a su enfermendad, aconsejaron definitivamente a Jaime II ordenar su traslado a Almazán y después a Aragón ya en la primavera de $1320^{24}$.

\footnotetext{
${ }^{20}$ Salvador de Moxó, La sociedad política castellana en la época de Alfonso XI "Cuadernos de Historia", 6 (1975), pp. 187-326. y De la nobleza vieja a la nobleza nueva. Las transformaciones nobiliarias castellanas en la Baja Edad Media, "Cuadernos de Historia" 3 (1969), pp. $1-210$.

${ }^{21} \mathrm{ACA}, \mathrm{C}$, reg. 245, fol. 161

${ }^{22}$ Ángeles MASIÁ DE RoS, Relación castellano-aragonesa, ob. cit., tomo I, pp. 198-202.

${ }^{23}$ Regina SÁINZ DE LA MAZA LASOLI, El Monasterio de Sijena. Catálogo de documentos del Archivo de la Corona de Aragón, I (1208-1348), Barcelona, 1994. Ver los regestos documentales números 473, 475 y 480.

${ }^{24} \mathrm{~J}$. Ernesto MARTínez Ferrando, Jaime II de Aragón, ob.cit., pp. 112-115. y Ángeles MASIÁ DE ROS, Relación castellano-aragonesa, ob.cit. pp.201-202.
} 
Nadie en la sociedad política castellana próxima a los círculos del poder monárquico, ni siquiera el infante don Felipe, censuró el precipitado exílio de doña María, sino fuera porque la infanta, que había dado a luz en agosto de 1319 en Alcocer, se llevaba consigo a Calatayud, a doña Blanca, hija del infante don Pedro, nieta de doña María de Molina y también de Jaime II y dueña de un estratégico patrimonio en las fronteras de Castilla con Aragón ${ }^{25}$.

Sólo don Juan Manuel, temporalmente avenido con doña María de Molina y convertido en flamante pretendiente a la tutoría del rey, a la espera de las próximas Cortes de Valladolid de 1321, y su esposa doña Constanza, insistieron ante Jaime II para que la infanta y su hija permanecieran todavía en Castilla, ahora bajo su protección familiar ${ }^{26}$. ¿Pretendía el astuto señor de Peñafiel acrecentar su prestigio y partidarios con esta medida?. Con la infanta doña María y su hija en su poder, don Juan Manuel aseguraba el apoyo de su suegro, amortiguaba las violencias de la bandería del infante don Felipe y sobre todo se apoderaba del importante patrimonio de su sobrina política. Esta fue una de las muchas causas vacuas del conflicto interno que le enfretaría entre 1321-1324 con el infante don Felipe y también con García Lasso de la Vega ${ }^{27}$.

Así pues, la futura residencia de doña Blanca sería objeto de frecuentes fricciones fronterizas entre Aragón y Castilla, entre doña María de Molina, Alfonso XI y Jaime II. Y en todo ello, una vez más, la infanta doña María estaba destinada a jugar un papel fundamental como madre y custodia de la niña en los últimos años de la minoría del rey castellano.

A la desaparición del infante don Pedro se le añadieron otras circuntanscias que abundaron en los problemas castellano de la infanta đoña María. La elección en 1319 para la sede arzobispal de Toledo del infante don Juan de Aragón, hijo también de Jaime II, levantaría muchas suspicacias antre los nobles y la iglesia castellana, en el infante don Felipe y la reina doña María de Molina. Don Juan llegó a la mitra toledana por la intervención directa del rey de Aragón en Aviñón y la mediación castellana de don Juan Manuel a cambio del reconocimiento a la tutoría del rey y del oficio de canciller mayor de Castilla. Para la mayor parte de la sociedad política

\footnotetext{
${ }^{25}$ J. Ernesto MARTínez FERRANDO, Jaime II de Aragón, ob.cit., pp. 114-115.

${ }^{26}$ Crónica de Alfonso XI, Ed. de Cayetano Rosell, BAE, Madrid, 1953, I, p. 188.

${ }^{27} \mathrm{ACA}, \mathrm{C}$, reg. 1521 , fols. 133 r.-133 v. y reg. 247 , fol. $140 \mathrm{v}$.
} 
castellana el nuevo arzobispo de Toledo era un extraño, resultado sólo de la prepotencia de Jaime II y su injerencia en los asuntos internos del reino. Desde su llegada don Juan actuó siempre en la defensa de los intereses familiares y señoriales de su hermanas doña Constanza y doña María frente a doña María de Molina porque "la reyna fizo e faze de don Johan, nuestro fijo, eleito de Toledo, muy grant desaguisado e sin razón" ${ }^{28}$. Aunque una revisión de su actuación nos descubre que en líneas generales don Juan se mostraría casi siempre imparcial en los bandos nobiliarios de los tutores don Juan Manuel y don Felipe, lo que disgustaría a ambos, ajeno algunas veces a la política peninsular de su padre y procurando siempre el bien común y la tranquilidad social de su arzobispado. En cualquier caso, la presencia del infante aragonés en Toledo hasta 1327 atendiendo las reclamaciones de su hermana doña María y de su hija doña Blanca, le enfrentaría en numerosas ocasiones con García Lasso de la Vega, con el infante don Felipe, con Alvar Nuñez de Osorio y otros nobles castellanos, abundando en el descrédito de su hermana en la corte castellana ${ }^{29}$.

Más grave para la situación de doña María fueron los conocidos sucesos de Gandesa. Como es bien sabido, en el concierto matrimonial de 1312 entre doña María y el infante don Pedro se había pactado también el de doña Leonor, hermana de Alfonso XI, con don Jaime, heredero del rey de Aragón. La infanta castellana fue entregada a la custodia y educación de Jaime II. Pero al no concretarse ni consumarse la ceremonia nupcial en Gandesa en el otoño de 1319 , la infanta doña Leonor fue devuelta a Castilla en junio del año siguiente ante la condena castellana y las muchas explicaciones de Jaime II a la reina ${ }^{30}$. Para la infanta doña María, para el porvenir de su hija doña Blanca, Gandesa fue una herida que jamás cicatrizó. Una llaga abierta por la que doña María de Molina, el infante don Felipe y su bandería nobiliaria observaron una vez más el engaño y a la prepotencia de Jaime II $^{31}$. No obstante, el rey de Aragón mantuvo hasta su muerte una correspondencia fluida con doña Leonor. En 1323 proyectó incluso el matrimonio de la infanta castellana con su hijo don Pedro, conde Cabrera y

\footnotetext{
${ }^{28} \mathrm{ACA}$, C. reg. 245 , fol. 245 v. Manuel GARCía FERNÁNDEZ, Jaime II y la minoría de Alfonso XI, ob.cit., pp. 157-159.

${ }^{29} \mathrm{ACA}$, C. reg. 339, fol. 211 r, fol. 212 r. y fol. 226 r-v.

${ }^{30}$ Manuel GarCía FernándeZ, Jaime II y la minoría de Alfonso XI, ob.cit., pp. 154-155.

${ }^{31} \mathrm{~J}$. Ernesto MARTínEZ FERRANDO, Jaime II de Aragón, ob.cit., pp. 112-113.
} 
Ampurias. Pero los privados de Alfonso XI, el infante don Felipe, Alvar Nuñez de Osorio y García Lasso de la Vega, exigieron en contrapartida la devolución de la infanta doña Blanca, que ya estaba en Aragón con su madre. Como Jaime II puso muchos reparos, el proyecto matrimonial fue olvidado por todos. Pues desde 1325 el joven Alfonso XI tenía otros compromisos más interesantes para su prima ${ }^{32}$.

Si defintivamente la infanta doña María y su hija doña Blanca marcharon a Calatayud por iniciativa propia, o bien por obediencia a los muchos ruegos y consejos de Jaime II, o simplemente obligadas por las cincunstancias castellanas adversas, nunca lo sabremos del todo. Pero en Castilla el exilio de doña María con doña Blanca sin previa autorización de la reina doña María de Molina fue motivo mas que suficiente de una tirantez endémica entre la infanta aragonesa y la reina de Castilla, y posteriormente entre los nobles castellanos que administraban los patrimonios de la nieta de Jaime II y el propio rey de Aragón hasta su muerte en 1327. Pues la residencia aragonesa de doña Blanca se prolongaría en el tiempo hasta los tratados de Agreda-Tarazona de 1329 firmados entre Alfonso XI y Alfonso IV.

\section{LA INFANTA DOÑA MARÍA EN ARAGÓN, $1320-1325$}

Durante los años que doña María permaneció en Aragón, primero junto a su padre, (1320-1322) y después como monja de Sijena (1322-1346), la política castellana de la infanta no adquiere casi nunca el protagonismo de la etapa anterior, tan vinculada al destino político del infante don Pedro. Desde 1319 ya sabemos que en Castilla el posible interés por la infanta doña María radicaba en la residencia y custodia de su hija doña Blanca. La hija del infante don Pedro había heredado de su padre un vastísimo patrimonio señorial fronterizo con Aragón de alto valor estratégico. El tutor de doña Blanca no sólo disfrutaría y administraría sus rentas, sino también gestionaría su posible matrimonio. Y esto era lo suficientemente importante como para

\footnotetext{
${ }^{32}$ ACA, C. cr. 9278 y reg. 339 , fols. 227 v-228 r.
} 
despertar la codicia entre los diferentes parientes y vasallos próximos al rey de Aragón y de Castilla ${ }^{33}$.

Sin pretenderlo, doña Blanca se convertiría en un personaje clave en la relaciones castellano-aragonesas durante los últimos años de la minoría de Alfonso XI y los primeros del gobierno personal del rey. Si Jaime II retenía a su nieta, contra la voluntad de su abuela paterna doña María de Molina y ante la aparente inhibición de su madre la infanta doña María, y la convertía en un arma de notable interés y negocio matrimonial; el infante don Felipe, García Lasso de la Vega y el propio Alfonso XI confiscaban progresivamente sus rentas y patrimonios castellanos ante las frecuentes protestas del rey de Aragón. En Castilla una infanta pobre, sin dote, y con problemas políticos tenía escasas posibilidades matrimoniales a pesar de la realeza de su sangre y el interés de Jaime $\mathrm{II}^{34}$.

Desde la perspectiva castellana del conflicto, el pensamiento y el proceder de la infanta doña María en todo este complicado asunto de la residencia de su hija no aparece tan claro como pretende la documentación editada por J. Ernesto Martínez Ferrando y Ángeles Masiá de Ros.

Efectivamente, poco después de la muerte de la reina doña María de Molina en 1321, la bandería del infante don Felipe llevó la guerra a la frontera de Aragón, a los patrimonios de doña Blanca gobernados por hombres fieles a la infanta y según "fuero, uso e costumbres de Aragón e a provecho de la dita infanta", exigiendo de Jaime II la inmediata devolución de la niña ${ }^{35}$. En la trama castellana de este asunto familiar el rey de Aragón se mostraba muy incómodo y contradictorio. Por un lado, parece resuelto a mantener a su hija y a su nieta a su lado por múltipes conveniencias políticas y mientras la actitud del infante don Felipe y García Lasso de la Vega fuera tan inquieta y ambiciosa y las fricciones fronterizas continuaran. Por otro, la escasa docilidad paterna de doña María le conminan a recluirla definitivamente en el Monasterio de Sijena y a tomar el hábito de San Juan de Jerusalén, al lado de su hermana doña Blanca del que era ya priora desde

\footnotetext{
${ }^{33}$ Manuel GARCíA FeRnÁNDEZ, Jaime II y la minoría de Alfonso XI, ob.cit., pp. 161-162.

${ }^{34} \mathrm{ACA}$, C. reg. 246, fol. 219 r-v.

${ }^{35}$ ACA, C. cr. 6861 y reg. 247 , fol. 27 r-v.
} 
$1321^{36}$. Para Jaime II esta fue la medida más segura para controlar a su hija y al mismo tiempo tenerla siempre cerca, y a su nieta, lógicamente.

Pero en Castilla la repentina vocación religiosa de la infanta aragonesa no se entendía del todo. Había cierto frasfondo social que se escapaba a la interpretación más lineal de los hechos. En los mismo días en los que Jaime II procedía a la reordenación de la nueva casa de la infanta monja, ante la insuficiencia de las rentas castellanas ${ }^{37}$, doña María, con entera independencia de su padre, para salvar los interes económicos de su hija, cansada tal vez de la excesiva dependencia paterna y de su forzada vinculación política, pactaba en el castillo de Deza con García Lasso de la Vega la regulación del patrimonio castellano de su hija y lo más importante nada menos que el futuro matrimonio de doña Blanca con su primo Alfonso XI tras su devolución al infante don Felipe en espera de la edad necesaria para celebrar el matrimonio. El paso siguiente era comunicarlo al rey de Aragón. En marzo de 1322 García Lasso de la Vega notificaba a Jaime II el pacto firmado con doña María y le pedía la inmediata restitución de su nieta a Castilla ${ }^{38}$

Aunque el rey de Aragón tenía serias dudas en la consecución de la necesaria dispensa papal - los futuros contrayentes eran primos hermanosy así se lo había notificado a su hija doña María y también a García Lasso de la $\mathrm{Vega}^{39}$ el brillo de una posible corona para su nieta parecía en principio halagarle. Pero, ¿estaba realmente satisfecho Jaime II con el pacto firmado en Deza?. ¿Pensaba devolver doña Blanca a Castilla y entregarla al infante don Felipe sin ninguna contrapartida?. Creemos que no. En cualquier caso, en marzo de 1322, tras perdonar a la infanta su atrevimiento y posiblemente contrariado, prometió a García Lasso de la Vega guardar y respetar todo lo pactado con su hija doña María. Se trataba sólo de ganar

\footnotetext{
${ }^{36}$ Regina SÁINZ DE la MAZA LASOLI, El Monasterio de Sijena, ob. cit. I, pp. XVII-XVIII y documentos ns. 537 y 539 .

${ }^{37}$ Regina SÁINZ DE la MAZA LASOl, El Monasterio de Sijena, ob. cit., I, documento n. 558

${ }^{38} \mathrm{ACA}$, C. reg. 247 , fols. $21 \mathrm{r}-22 \mathrm{v}$ y reg. 339, fol. $379 \mathrm{r}$-v. Manuel GARCÍA FERNÁNDEZ, Jaime II y la minoría de Alfonso XI, ob. cit., pp. 162.

${ }^{39} \mathrm{ACA}, \mathrm{C}$. reg. 247. fol. 46 r-v. Andrés GiménEz Soler, Don Juan Manuel, ob. cit., pp. $502-503$
} 
tiempo. De esperar la negativa pontifícia del enlace proyectado en Deza para pasar a la ofensiva contra Lasso de la Vega ${ }^{40}$.

Mientras tanto en Castilla el pacto de Deza debió interpretarse como un éxito político del infante don Felipe y su bandería nobiliaria. Para García Lasso de la Vega y otros nobles de su influencia los compromisos firmados con doña María, a espaldas del rey de Aragón, tenían como finalidad asegurar la tranquilidad social necesaría hasta alcanzar la mayoría edad del rey Alfonso XI. Y en todo ello la residencia de doña Blanca y sus patrimonios señoriales $-y$ en menor medida la suerte de su madre- jugaban un papel decisivo a fin de evitar negocios diplomáticos ajenos a los interes de la corona castellana.

Pero en Deza concluyó la intervención directa de doña María en la defensa de los patrimonios castellanos heredados del infante don Pedro. Jaime II acentuaría su progresiva reclusión en Sijena - con tres dueñas que le acompañarian siempre- al tiempo que obstaculizaba su salida hacia Castilla con doña Blanca, según lo firmado, y desconfiaba de la entrada de García Lasso de la Vega en Calatayud para hablar con la infanta doña María y ver a su hija en 1323. Por lo que proyecto matrimonial fue lentamente olvidado por todos en un ambiente de frecuentes agresiones fronterizas mútuas hasta $1325^{41}$.

Sólo a partir de entonces, Jaime II pasó a la ofensiva y buscó en Castilla, sin consulta ni mediación alguna de su hija doña María, un marido para su nieta doña Blanca. Y lo encontró en don Juan de Haro, "el tuerto", hijo del infante don Juan, señor de Vizcaya, enemigo declarado del infante don Felipe, de García Lasso de la Vega y de Alvar Nuñéz de Osorio, los nuevos privados del monarca castellano. Un hombre de prestigio, capaz de afianzar al rey de Aragón en su predominio peninsular, de introducirlo denuevo como habil mediador de las viejas banderías nobiliarias castellanas. Un poderoso rico hombre de Castilla, serio aspirante todavía a participar en el gobierno de la casa del rey, que se convertiría de inmediato en el custodio y guardián de los patrimonios de doña Blanca ante los desordenes y las violencia de García Lasso de la Vega y sus hijos ${ }^{42}$.

\footnotetext{
${ }^{40}$ ACA, C. reg. 247 , fols. 21 r-v, y 22 v- 23 r. Ed. por Ernesto MARTínez FerRando, Jaime II de Aragón, ob.cit, II, pp. 280-281 y 282-283.

${ }^{41}$ Ernesto MaRTínez FERRANDO, Jaime II de Aragón, ob.cit., pp. 121-124.

${ }^{42}$ Manuel García FeRnÁNDEZ, Jaime II y la minoría de Alfonso XI, ob.cit. p. 162 y pp. 163-167.
} 
Desconocemos el pensamiento de la infanta en todo este coplicado asunto matrimonial. Aunque no debió disgustarle. La desastrosa situación de su hacienda, por las frecuentes confiscaciones de sus rentas y patrimonios castellanas desde 1322 a 1325, le hicieron sospechar de García Lasso de la Vega y sus hijos. Las relaciones entre su antiguo mayordomo mayor, ahora también justicia mayor de la casa de rey de Castilla, se hicieron cada vez más tirantes, imposibles. Pues el hombre con quien había pactado en Deza, no sin grandes sacrificios familiares, la normalización de sus problemas castellanos resultaba ser ahora en 1325 su principal enemigo.

Con la mayoría de edad de Alfonso XI y la dimisión forzosa de los antiguos tutores - don Felipe, don Juan Manuel y don Juan de Haro- en las Cortes de Valladolid de 1325, aparecen junto al rey hombres nuevos con ideas nuevas; Alvar Nuñez de Osorio, García Lasso de la Vega y su hijo Pedro, Juan Martinez de Leiva, etc. Todos ellos eran integrantes de la bandería política del don Felipe, contrarios a don Juan Manuel, a don Juan el "tuerto" y a toda influencia aragonesa en la corte y en la sociedad política castellana. Con estos hombres Alfonso XI proyectaba la reconstrucción de la autoridad monárquica en Castilla, en la que evidentemente ni Jaime II ni su hija, la infanta doña María, entraban ${ }^{43}$.

En este sentido, uno de las primeras actuaciones del rey de Castilla fue desvaratar el peligroso proyecto matrimonial concertado por Jaime II entre don Juan de Haro y doña Blanca. En Aragón el enlace se justificó por su finalidad económica. El señor de Vizcaya se convertiría en paladín castellano de los patrimonios de su futura esposa y mediaría ante Alfonso XI para que las villas y castillos de doña Blanca reconociesen la autoridad de Jaime II como administrador de los bienes de su nieta hasta la celebración de las bodas ${ }^{44}$.

Pero en Castilla el acuerdo se interpretó siempre como un peligroso asunto político. La nueva monarquía de Alfonso XI no podía tolerar que el vasto patrimonio del infante don Pedro cayese en manos de don Juan de Haro porque se constituiría un señorio fronterizo con Aragón de notables proporciones y bases de futuras operaciones contra el rey de Castilla. Así lo expresa Fernán Sanchez de Valladolid, secretario de la poridad en la Crónica

${ }^{43}$ ACA, C. cr. 9277 y 9061 . Manuel GARCía FERNÁNDEZ, Jaime II y la minoría de Alfonso $X I$, ob. cit. p. 164.

${ }^{44} \mathrm{ACA}$, C. reg. 249 , fols. $27 \mathrm{r}-28 \mathrm{v}$. 
de Alfonso XI: "en este tiempo era en Aragón doña Blanca, hija del ynfante don Pedro de Castilla, con la ynfanta doña María su madre, hija del rrey don Jaymes de Aragón. Y esta doña Blanca avie en el rreyno de Castilla muchas villas e castiellos e lugares muy fuertes, e los mas dellos en la frontera de Aragón, e como quiera que don Joan fuese muy poderoso en los rreynos de Castilla e de Leon, entendio que si el casava con esta doña Blanca, que con lo que el avia e avia doña Blanca que podria hazer gran daño al rrey en el rreyno"45.

Ajena a esta situación castellana, la infanta doña María observó impotente como entre 1325-1326 los privados del rey de Castilla desvarataban progresivamente la trama aragonesa tejida durante la minoría de Alfonso XI por Jaime II con la diligente influencia de su hija. Primero desmembraron la alianza familiar entre don Juan Manuel y don Juan de Haro frente a Alfonso XI, al ofrecer el matrimonio del propio rey a Constanza Manuel, también nieta de Jaime II, con la evidente aprobación y satisfacción del rey de Aragón, para aislar después a don Juan de Haro de la ayuda militar de su principal valedor castellano. Segundo, algunos meses más tardes, Alvar Nuñez de Osorio pactaría con Alfonso IV de Portugal el compromiso matrimonial de doña Blanca con el heredero portugués don Pedro y el de Alfonso XI con su hija doña María. Doña Constanza Manuel fue repudiada y retenida en Toro, lejos de su padre. Jaime II se decidió a intervenir directamente.

En las fronteras entre Castilla y Aragón la guerra era una realidad constrastada. Los privados de Alfonso XI, entre ellos García Lasso de la Vega y su hijo Pedro Lasso de la Vega, quienes en teoria deberían defender los patrimonios de doña Blanca, lo saqueaban y raciaban violentamente ahora llegando a las puertas de Calatayud, ante la incomprensión de su madre doña María ya nonja de Sijena. Por su parte, don Juan Manuel alborataba las tierras del rey en Murcia y don Juan de Haro hacía lo propio en Galicia, León y Vizcaya ${ }^{46}$. En noviembre de 1326 en la villa de Toro, García Lasso de la Vega ajustició a don Juan de Haro por orden del rey acusado de traidor. Sus patrimonios pasaron a la corona y como botín de guerra los privados se repartieron sus muchos señoríos ${ }^{47}$.

\footnotetext{
${ }^{45}$ Gran Crónica de Alfonso XI, ob.cit., I, p. 384.

${ }^{46}$ ACA, C. cr. 9061.

${ }^{47}$ Manuel GarCía FeRnánDEZ, Jaime II y la minoría de Alfonso XI, ob. cit. pp. 166-167.
} 
La muerte de don Juan arruinaba el último proyecto matrimonial castellano de doña Blanca. La infanta aragonesa doña María, nada podía hacer ya por la suerte de su hija. Poco antes de la muerte del rey de Aragón, en octubre de 1327 se firmaron los compromisos matrimoniales portugueses en Sevilla, aunque el matrimonio de la nieta de Jaime II tampoco se realizaria esta vez por la negativa del principe don Pedro y la evidente enajenación mental de doña Blanca. En enero de 1329, con motivo de las visitas de Agreda y Tarazona entre Alfonso IV de Aragón y Alfonso XI, "el rrey de Castilla vionose a su rreyno, e traxo consigo a doña Blanca hija del ynfante don Pedro el que murió en la Vega de Granada"48. Nada sabemos de la actitud de doña María, atareada sin duda con los avatares propios de su nueva situación junto a su hermana Blanca.

Recluída en el Monasterio de Las Huelgas de Burgos, donde estaba la tumba de su padre, la ingenua doña Blanca terminaba sus días. Alfonso XI le confiscó progresivamente sus bienes y desde 1336 los entregaba como "apanages" vitalicios a su hijos bastardos con doña Leonor de Guzmán. Pero esa es, evidentemente, otra historia ${ }^{49}$.

\section{RÉSUMÉ}

L'infante Marie, fille aînée du roi Jacques II d'Aragon, fut un personnage décisif et influent de la société politique castillane pendant la minorité d'Alphonse XI (1312-1325). Mariée à l'infant Pierre, oncle et tuteur du roi de Castille, elle se conforma aux directives poliques de son époux jusqu'à la mort de ce dernier en 1319. À partir de cette date, ses relations avec les milieux proches du pouvoir royal ne furent pas bonnes. L'administration de ses domaines seigneuriaux, hérités de l'infant Pierre, la naissance et l'éducation de sa fille Blanche ainsi que sa résidence aragonaise ou castillane constituèrent autant d'affaires que l'infante dut défendre de l'Aragon, du Monastère de Sijena, contre les convoitises de l'infant Philippe, de García Lasso de la Vega et du roi Alphonse XI lui-même. Cette étude a pour but l'analyse de toutes ces relations du point de vue castillan, en prenant comme base l'excellente documentation conservée dans les Archives de la Couronne d'Aragon (ACA), éditée depuis longtemps.

\footnotetext{
${ }^{48}$ Cran Crónica de Alfonso XI, ob. cit., I, p. 463. Ángeles MASIÁ DE Ros, Relación castellano-aragonesa, ob. cit. I, pp. 211-225.

${ }^{49}$ Ester GONZÁLEZ CRESPO, El afianzamiento económico y social de los hijos de doña Leonor de Guzmán, "Anuario de Estudios Medievales", 18 (1988), pp. 289-303.
} 


\section{SUMMARY}

The Infanta Doña María, the eldest daughter of James II of Aragon, was a decisive and influential personality in Castilian politics during Alfonso XI's minority years (13121325). Married to the Infante Don Pedro, uncle and tutor of the king of Castile, she would perform her duties consistently following the political guidelines of her husband until his death in 1319. Thenceforward, her relationships with the circles of royal power were not in good terms. Questions such as the government and administration of her feudal patrimonies, inherited from Don Pedro, and the birth of her daughter Blanca, as well as her education and residence in either Aragon or Castille, were all tackled by the Infanta from Aragon, from the Monastery of Sijena opposing the longing for power of both the Infante Don Felipe and García Lasso de la Vega, and even of king Alfonso XI himself. This essay aims at the analysis of these relationships from a Castilian perspective, making use of the excellent documentation kept in the ACA and edited from old. 